\title{
Design and Implementation of PLC based Elevator
}

\author{
S.B. Ron Carter \\ Dept of Electrical and Electronics Engineering, \\ Rajalakshmi Engineering College, \\ Chennai, India.
}

\begin{abstract}
This paper explains about an elevators operation which uses a AC motor to drive the elevator cabin. The elevator mentioned here is fully automated using PLC. Its control is based on the input that we get from the operator as well as from the sensors. According to that signal PLC will make the drive motor and door motor to work correspondingly.
\end{abstract}

\section{Keywords}

PLC based elevator, Elevator Design, Constant speed Elevator, Ladder logic for Elevator using PLC.

\section{INTRODUCTION}

Due to the cause of rapid population growth at the cities and multi-stored buildings, the need of elevators is being increased. With the rising life standards and attention to human and with the technologic developments, elevator systems are getting better, more fast, stronger and better quality elevators are produced. Previously, most systems were focused on the mounting of elevators, especially after the 1980s the need for elevator maintenance and fault staff have been started to increase. For instance, automatic doors have being used instead of splash doors, microprocessor electronic cards have being used instead of cards with relay, double-speed or speed-controlled elevators have being used instead of one-speed elevators. Such developments provide to improve the quality in elevator systems, develop and diverse the used setting and maintenance or repair tools and instruments and therefore facilitation of the work compared to previous years and increase the reliability of elevator. Some of the drawbacks of the traditional system are

$>$ The control system have high failure rate that were mainly due to numerous contacts, complexity of wiring circuit. In addition, electrical contacts were easy to burn out, which could result in poor contact.

$>$ Electrical controller and hardware wiring based on common method were difficult to achieve a more complex control function

\author{
A. Selvaraj \\ Dept of Electrical and Electronics Engineering, \\ Rajalakshmi Engineering College, \\ Chennai, India.
}

$>$ Electromagnetic actuator and contact action were so slow, mechanical and electromagnetic have large inertia. Therefore, the control precision of system was difficult.

Some of the developments that have made to overcome the disadvantages of previously used elevators are

- The traditionally used relays and IC boards have been replaced by PLC for easy and cheap controlling of machines used in the elevator.

- Also by the use of PLC we can integrate monitoring software's like Intouch, Citech, etc.

- In order to control the motion of the elevator cabin smoothly AC motors are used because of its advantage of easy controlling and fast acceleration and deceleration.

- To achieve high speed nine-phase Permanent Magnet Synchronous Motor has been used.

- To reduce the size of the machine room and for smooth operation Linear Induction Motor has been used.

- In some cases Linear Switched Reluctance Motor (LSRM) has been used because of the absence of windings both in stator as well as in the rotor even though it is having some disadvantages like difficulty in motor controlling and generation of ripples.

\section{DESIGN AND CALCULATION OF HARDWARE}

This chapter discuss about the design of an elevator by the calculation of certain parameters which defines the operation of the elevator. To meet the objectives of the project that has been derived from the previously completed theoretical studies a machine model has been designed. Then to validate and to implement the simulated model as a prototype certain calculations have been carried out to determine some critical parameters. The parameters includes the size of the cabin, maximum number of persons can be accommodated into the elevator, strength of the rope, type of motor used, motors power rating and torque rating. The important part of the system is the controller the type of controller used here is PLC. Electromagnetic actuator and contact action were so slow, mechanical and electromagnetic components have large inertia. Therefore, 
the control precision of system was difficult. So there is a need to go for modern type of controllers like PLC. In this type of control there is provision to monitor the entire system by means of SCADA.

\subsection{Block diagram}

Based upon the need the blocks have been developed and drawn as block diagram Figure 1. After the designing of the model, calculation has to be done for each and every component present in the model.

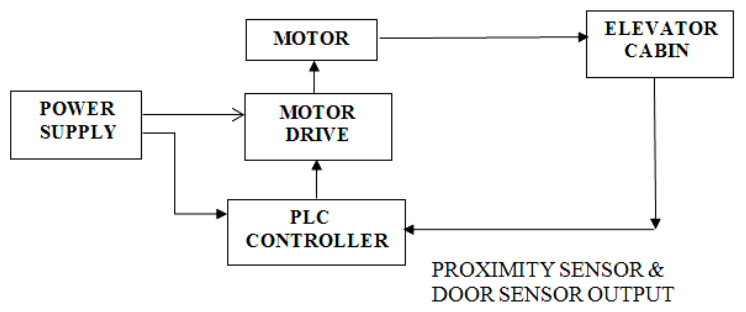

Fig 1: Block diagram of PLC based Elevator

Figure 1 depicts the block diagram of a PLC based Elevator. Supply is given to both the PLC controller as well as to the motor. This is attached with the elevator cabin with the use of proximity sensor (LDR) the position of the cabin will be determined and by using the door sensor (LDR) the position of the door is found out and the cabin is made to work accordingly. The drive system for the motor may have inverter with a rectifier or it may depends upon the type of power converter that the designer choose.

\subsection{Design of elevator cabin}

The elevator cabin is designed by having in mind the number of passengers it is going to accommodate. Also it should have the capacity to bear the weight of the passengers travelling in the elevator. The proposed elevator is having the capacity to accommodate approximately 10 persons of $65 \mathrm{~kg}$.

Maximum No. of passengers can be accommodated in the cabin $=10$

Approximate weight of each person $=650 \mathrm{~kg}$.

Maximum weight that the cabin can handle $=650 \mathrm{~kg}$.

To accommodate 10 persons the cabin has been designed with the following dimensions $5 \times 5 \times 7$. The mentioned dimensions are in feet.

For the sake of design simplicity the entire system has reduced to a prototype of 1: 20 ratio to the real model.

The tension on the rope and its choice of selection can be determined with the following simple calculation. The force excreted on the rope can be found by using Newton's formula.

\subsection{Rope strength}

The force which acts on the rope can be found out by the following calculation (1.1).

$$
\begin{gathered}
F=m g \\
F=(650+100+100) \times 9.8=8330 \mathrm{~N}=8.33 \mathrm{kN}
\end{gathered}
$$

The force acting on the string is $8.33 \mathrm{kN}$. So a string with the capacity to bear at least $9 \mathrm{kN}$ has to be chosen.

\begin{tabular}{|c|c|c|c|c|c|c|c|}
\hline \multicolumn{2}{|c|}{ Rope Diameter } & \multicolumn{2}{|c|}{$\begin{array}{l}\text { Minimum Breaking } \\
\text { Strength }\end{array}$} & \multicolumn{2}{|c|}{ Safe Load } & \multicolumn{2}{|c|}{ Weight } \\
\hline (in) & $(\mathrm{mm})$ & $\left(b ; b_{j}\right)$ & $(\mathrm{kN})$ & $\left(\mid b b_{j}\right)$ & $(\mathrm{kN})$ & $\left(\mid b_{m} / t t\right)$ & $(\mathrm{kg} / \mathrm{m})$ \\
\hline $1 / 4$ & 6.4 & 5480 & 24,4 & 1100 & 4.89 & 0.11 & 0.16 \\
\hline $5 / 16$ & 8 & 8520 & 37,9 & 1700 & 7.56 & 0.16 & 0.24 \\
\hline $3 / 8$ & 9.5 & 12200 & 54,3 & 2440 & 10.9 & 0.24 & 0.36 \\
\hline $7 / 16$ & 11.5 & 16540 & 73,6 & 3310 & 14.7 & 0.32 & 0.48 \\
\hline $1 / 2$ & 13 & 21400 & 95,2 & 4280 & 19.0 & 0.42 & 0.63 \\
\hline $9 / 16$ & 14.5 & 27000 & 120 & 5400 & 24.0 & 0.53 & 0.79 \\
\hline $5 / 8$ & 16 & 33400 & 149 & 6680 & 29.7 & 0.66 & 0.98 \\
\hline $3 / 4$ & 19 & 47600 & 212 & 9520 & 42.3 & 0.95 & 1.41 \\
\hline $7 / 8$ & 22 & 64400 & 286 & 12900 & 57.4 & 1.29 & 1.92 \\
\hline 1 & 26 & 83600 & 372 & 16700 & 74.3 & 1.68 & 2.50 \\
\hline $11 / 8$ & 29 & 105200 & 468 & 21000 & 93.4 & 2.13 & 3.17 \\
\hline $11 / 4$ & 32 & 129200 & 575 & 25800 & 115 & 2.63 & 3.91 \\
\hline $13 / 8$ & 35 & 155400 & 691 & 31100 & 138 & 3.18 & 4.73 \\
\hline $11 / 2$ & 38 & 184000 & 818 & 36800 & 164 & 3.78 & 5.63 \\
\hline $15 / 8$ & 42 & 214000 & 852 & 42800 & 190 & 4.44 & 6.61 \\
\hline $13 / 4$ & 45 & 248000 & 1100 & 49600 & 221 & 5.15 & 7.66 \\
\hline $17 / 8$ & 48 & 282000 & 1250 & 56400 & 251 & 5.91 & 8.80 \\
\hline 2 & 52 & 320000 & 1420 & 64000 & 285 & 6.72 & 10.0 \\
\hline
\end{tabular}

Table 1. Rope strength table

From the rope manufacturer's data sheet Table 1, for our requirement we can go for the cable with $10.9 \mathrm{kN}$ safe load capacity and thickness of $3 / 8$ inor $9.5 \mathrm{~mm}$.

\subsection{Power calculation for motor}

The motor used here is a capacitor start single phase induction motor. Based on the design specification the output power and the output torque of the motor are calculated by a simple calculation.

Power and torque calculation

$$
\text { Weight of empty cabin }=100 \mathrm{~kg}
$$

Counter weight $=100 \mathrm{~kg}$

10persons with $65 \mathrm{~kg}=650 \mathrm{~kg}$

For constant speed operation of $1 \mathrm{~m} / \mathrm{s}=60 \mathrm{~m} / \mathrm{min}$

The power, work and force are calculated using the equations (1.2), (1.3), (1.4) and (1.5)

$$
\begin{aligned}
& \text { Power }=\text { work } / \text { time } \ldots \ldots \ldots \ldots(1.2) \\
& \text { Work }=\text { Force } \times \text { distance } \ldots \ldots \ldots . . \\
& \text { Force } F=m g
\end{aligned}
$$


So, Power $=$ Force $\times$ velocity

$$
\begin{aligned}
& F=650 \times 9.8=6370 \mathrm{~N} \\
& P=6370 \times 1 \mathrm{~m} / \mathrm{s}=6370 \mathrm{~W} \\
& 1 \mathrm{hp}=745 \mathrm{~W} \\
& 6370 \mathrm{~W}=8.55 \mathrm{hp} \text { approx } 9 \mathrm{hp} \text { or } 6705 \mathrm{~W} \\
& \text { Rotational Speed } \omega=1500 \mathrm{rpm}
\end{aligned}
$$

The torque of the motor can be calculated by using the equation (1.6),

$$
\begin{aligned}
\text { Torque of motor } & (\mathrm{Nm})=\frac{\text { Power in Watts }}{2 \pi \omega} \ldots . \\
& =6705 /(2 \pi \times 1500) \\
& =31.5 \mathrm{Nm}
\end{aligned}
$$

Prototype of 1:20 ratio

Weight of empty cabin $=5 \mathrm{~kg}$

Counter weight $=5 \mathrm{~kg}$

10persons with $3.25 \mathrm{~kg}=325 \mathrm{~kg}$

For constant speed operation of $1 \mathrm{~m} / \mathrm{s}=60 \mathrm{~m} / \mathrm{min}$

The power, work and force are calculated using the equations (1.2), (1.3), (1.4) and (1.5)

$$
F=32.5 \times 9.8=318.5 \mathrm{~N}
$$

Therefore, Power $P=318.5 \times 1 \mathrm{~m} / \mathrm{s}=318.5 \mathrm{~W}$

$$
1 \mathrm{hp}=745 \mathrm{~W}
$$

$318.5 W=0.427$ hp approx 0.5 hp or $372.5 W$

$$
\begin{aligned}
\text { Rotational Speed } \omega & =1500 \mathrm{rpm} \\
\text { Torque of motor }(\mathrm{Nm}) & =\frac{\text { Power in Watts }}{2 \pi \omega} \\
& =\frac{372.5}{2 \pi \times 1500} \\
& =1.749 \mathrm{Nm}
\end{aligned}
$$

\subsection{Gear calculation}

To achieve the desired speed of $1 \mathrm{~m} / \mathrm{s}$ from the motor output of $1500 \mathrm{rpm}$ we are going for a calculation to find out diameter and the circumference of the gears.

Cabin weight is $100 \mathrm{~kg}$

Counter weight is $100 \mathrm{~kg}$

10 persons with $65 \mathrm{~kg}=650 \mathrm{~kg}$

Speed of the elevator is $1 \mathrm{~m} / \mathrm{s}$

$$
=60 \mathrm{~m} / \mathrm{min}=6000 \mathrm{~cm} / \mathrm{min}
$$

Circumference of gear $2, C_{2}=30 \mathrm{~cm}$

$$
\therefore \text { Diameter of gear } 2, \begin{aligned}
d_{2} & =\frac{\text { Circumference }}{\pi} \\
& =30 / \pi=9.5 \mathrm{~cm}
\end{aligned}
$$

To find the rpm of gear2

$$
\begin{aligned}
& r p m=\frac{\text { velocity }}{\text { circumference }} \\
& \left.\therefore \frac{6000}{30}=200 \mathrm{rpm} \text { (Speed of gear } 2\right)
\end{aligned}
$$

$$
\text { Speed of gear } 1=1500 \mathrm{rpm}
$$

Speed (rpm) and length are inversely proportional

$$
\begin{aligned}
& \therefore \frac{200}{1500}=\frac{\text { Circumference of gear } 1\left(C_{1}\right)}{30} \\
& \therefore \text { Circumference of gear } 1, C_{1}=4 \mathrm{~cm}
\end{aligned}
$$

$$
\therefore \text { Diameter of gear } 1, \begin{aligned}
d_{1} & =\frac{\text { Circumference }\left(C_{1}\right)}{\pi} \\
& =\frac{4}{\pi} \\
& =1.273 \mathrm{~cm}
\end{aligned}
$$

For smooth meshing of gears both the gears should have same sized teeth so it should have same pitch $p$. The pitch can be calculated using the equation (1.7).

$$
p=\frac{2 \pi r_{d 1}}{N_{d 1}}=\frac{2 \pi r_{d 2}}{N_{d 2}}
$$

Take the number of teeth be 8 ( 1 tooth for every 45 degree)

$$
p=\frac{4}{8}=0.5
$$

From ' $p$ ' the value of ' $N_{d 2}$ ' can be found out

$$
\begin{aligned}
N_{d 2} & =\frac{2 \pi r_{d 2}}{p} \\
& =\frac{30}{0.5} \\
\therefore N_{d 2} & =60 \text { teeth }
\end{aligned}
$$

Therefore, the gear ratio is given by,

$$
\begin{aligned}
R & =N_{d 1}: N_{d 2} \\
& =1: 7.5
\end{aligned}
$$

\subsection{Sensor using LDR}

Light Dependent Resistor is a component which changes its resistance across it when the intensity of light falling over it changes. So this property of the LDR is utilized to make a sensor circuit and LDR is fixed as one of the two resistances present in the potential divider circuit. 


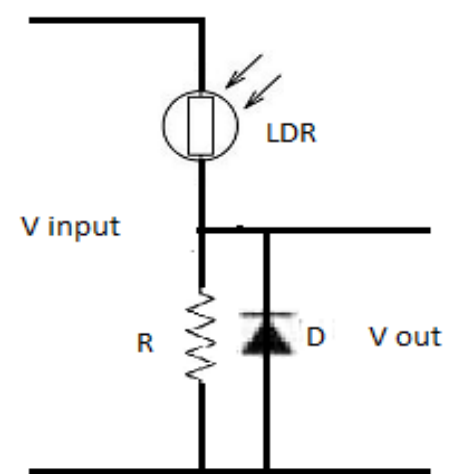

Fig 2: Sensor Circuit using LDR

Figure 2 is the modified potential divider circuit modification is done by the addition of LDR and diode.

The output voltage across the resistance ' $R$ ' is calculated by the following equation

$$
V_{\text {out }}=\frac{V_{\text {in }} \times R_{L D R}}{\left(R_{L D R}+R\right)}
$$

Where $R_{L D R}$ the resistance is across the LDR and $R$ is the resistance across resistor $\mathrm{R}$.

The output voltage $V_{\text {out }}$ is given to the relay once the relay get excited its energy has to be release otherwise the relay wont operate properly so a diode is connected across the resistor $\mathrm{R}$.

\subsection{Controller design}

The controller used here is a Programmable Logic Controller (PLC) as this shows sharp advantages over the preexisting relay type of controllers. Relay type of controllers having complicated wiring so its drawbacks have been over by these PLCs. The PLC used here is GE FANUC Versamax. It is having 16 DC inputs and 11 relay outputs. The supply of $24 \mathrm{VDC}$ has to be given to the PLC. It can accommodate up to $32 \mathrm{I} / \mathrm{O}$ ports. In this project maximum number of sensors has been used. So depend upon the number of sensors used we may have to include extra I/O modules. Corresponding to the type of sensors chosen the I/O ports have to be assembled with the PLC it may be analog or digital ports. For safe operation during emergency situation a separate RUN/STOP manual switch is provided in the module itself. Signal can be transmitted through serial port (RS 232) or through Ethernet but the amount of data transferred depends on the type communication type we choose. GE FANUC Versamax PLC is having a configurable memory of $64 \mathrm{~KB}$.

\section{WIRING OF VERSAMAX 1C200UDR010}

Figure 3 depicts the wiring of PLC IC200UDR010. The terminals from $\mathrm{C} 1$ to $\mathrm{C} 4$ in the input side and terminal from $\mathrm{C} 1$ to $\mathrm{C} 7$ in the output side describes the common points where any one of the terminals of either the load or the source has to be connected.

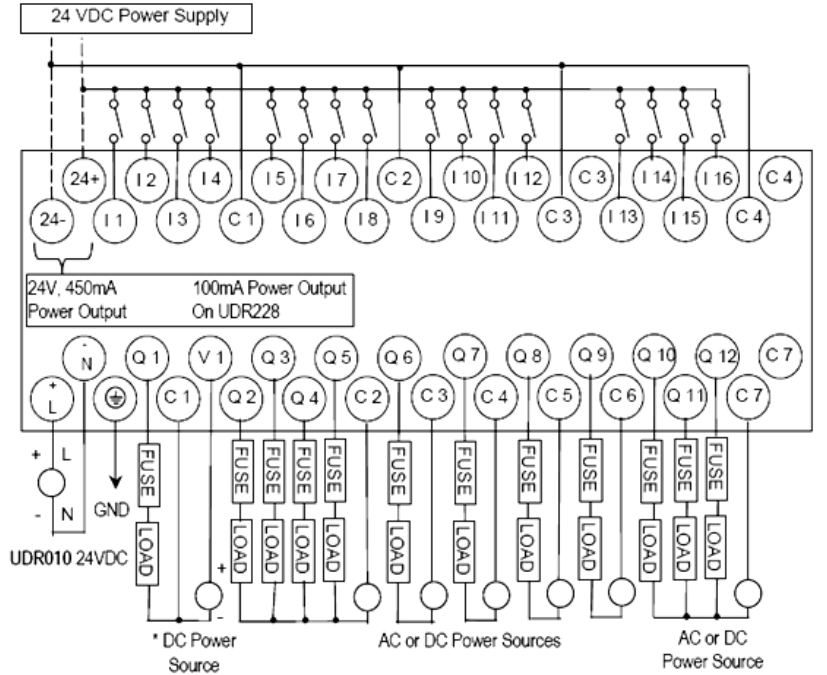

Fig 3: Wiring of Versamax IC200UDR010

All the inputs of the PLC should be $24 \mathrm{~V} \mathrm{DC}$ but it will be activated by a voltage anywhere in between $20 \mathrm{Vdc}$ and $30 \mathrm{Vdc}$. The first output Q1 is a DC whereas the other outputs are connected with relay so both the DC and AC sources can be used based on our requirements

\section{LADDER LOGIC}

This chapter discusses about the development of ladder logic network. Based on our requirements the logic has to be developed also depending on the need, the relevant PLC has been chosen. Here VersaPro 2.02 has been chosen for developing and to download ladder logic into the PLC. For the working model of an elevator various logics for different operations have to be developed and it is discussed in the following subtitles

\subsection{Logic for getting input from call buttons and to latch}

As an initial move the ladder logic has to be developed for receiving the input signal from the call buttons and the same is used with the program to get the corresponding output based on this input. Once the PLC receives the signal the corresponding bit will be latched.

Table 2. Input Address

\begin{tabular}{|c|c|c|}
\hline Sl.No & Inputs & Operation \\
\hline 1 & $\% \mathrm{I} 00001$ & G-Floor \\
\hline 2 & $\% \mathrm{I} 00002$ & $1^{\text {st }}$ Floor Up \\
\hline 3 & $\% \mathrm{I} 00003$ & $2^{\text {nd }}$ Floor Up \\
\hline 4 & $\% \mathrm{I} 00004$ & $3^{\text {rd }}$ Floor \\
\hline 5 & $\% \mathrm{I} 00005$ & $1^{\text {st }}$ Floor Down \\
\hline 6 & $\% \mathrm{I} 00006$ & $2^{\text {nd }}$ Floor Down \\
\hline
\end{tabular}

Figure 4 and Table 2 describes the logic that has been developed to get the inputs from the call buttons present at every floor. When a particular switch from the corresponding 


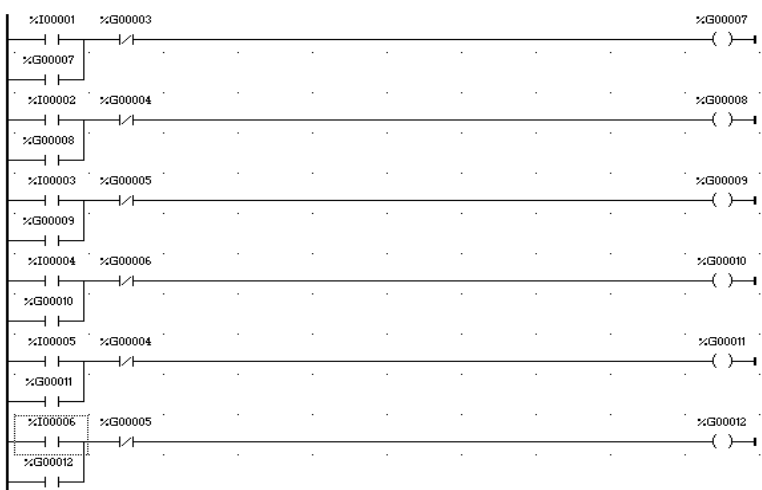

Fig 4: Ladder Logic for getting input from call buttons and to latch

floor has been pressed the program in the PLC gets activated and the relevant bit will be latched. The latching will be there until that bit has been unlatched by another bit.

After getting the inputs from the call buttons the bits are latched. The various Bits used for latching the corresponding input signals from the call buttons are mentioned below.

Table 3. Latching Bits

\begin{tabular}{|c|c|c|}
\hline Sl.No & Inputs & Bits to Latch \\
\hline 1 & $\% \mathrm{I} 00001$ & $\% \mathrm{G} 00007$ \\
\hline 2 & $\% \mathrm{I} 00002$ & $\% \mathrm{G} 00008$ \\
\hline 3 & $\% \mathrm{I} 00003$ & $\% \mathrm{G} 00009$ \\
\hline 4 & $\% \mathrm{I} 00004$ & $\% \mathrm{G} 00010$ \\
\hline 5 & $\% \mathrm{I} 00005$ & $\% \mathrm{G} 00011$ \\
\hline 6 & $\% \mathrm{I} 00006$ & $\% \mathrm{G} 00012$ \\
\hline
\end{tabular}

\subsection{Logic for motor operation and to get} signal from the floor sensors

The next step of receiving the input signal is to make the motor to operate either in forward or in reverse direction and the logic has been developed correspondingly.

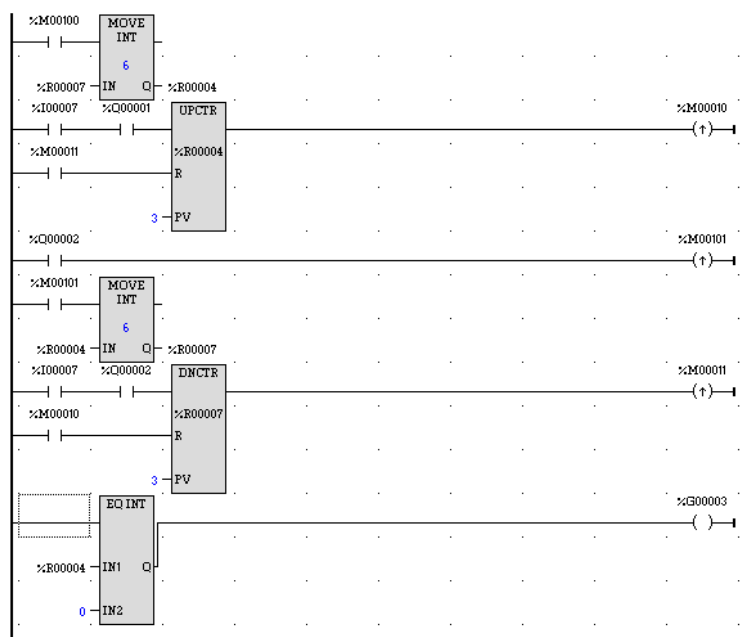

Fig 5: Ladder Logic for motor operation and to get signal from the floor sensors
Figure 5 shows the snap shot of the logic for the motor operation in both reverse and forward direction. The motor operation is purely based on the input that the PLC gets from the call buttons. In this Figure the operation of floor sensor has also been mentioned and explained. Based on the desired input and corresponding floor the PLC will make the motor to stop.

Outputs used for motor operation

1) Forward motoring- $\% \mathrm{Q} 00001$

2) Reverse motoring- $\% \mathrm{Q} 00002$

Floor sensors: \%I00007

The output of LDR sensor for finding the floor is connected with the input terminal \%I00007 of the PLC. In order to reduce the number of inputs counter has been used, corresponding to the counting in the counter the PLC will make the motor to stop.

\subsection{Logic for door opening}

Once the operation of the elevator motor ceases the logic has to be developed in such a way that it facilitates the door opening. Based on the inputs from the call buttons, the floor sensors and the program downloaded in the PLC the door will open and close. That is the motor will operate either in forward direction or rotate in the reverse direction. The various input and output ports used in this logic are,

1) Door opening-\%Q00003

2) Door opening sensor-\%I00011

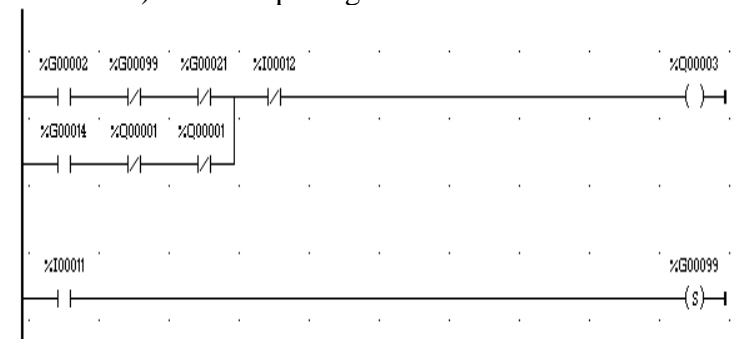

Fig 6: Ladder Logic for door opening

Figure 6 describes the operation of door motor. According to our logic when both the forward and reverse motoring of the elevator motor stops the door opening logic gets latched. So the output $\% \mathrm{Q} 00003$ will be forced to ON at the end of door opening the sensor \%I00011 will be latched this latching will make the door opening motor to stop. This operation will initiate the next process of door closing.

\subsection{Logic for door closing}

The process of door closing has to start once the door has been fully opened so a sensor is placed at the end of door opening and when the sensor is cut a signal will be sent to the PLC. 


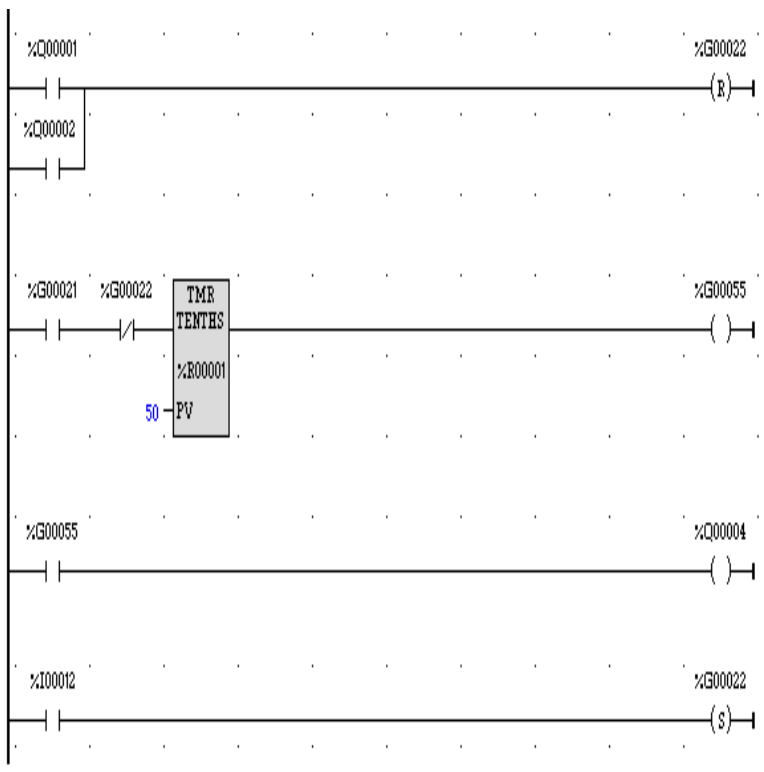

Fig 7: Ladder Logic for door closing

Figure 7 describes the operation of door closing once the door opening operation comes to end that is when the sensor present at end for door opening has been cut. The ON-Delay Timer will be activated this will provide a delay of 5 seconds before the door closes. After the delay the door motor starts to rotate in the reverse direction thus initiating the door closing operation. At the end of door closing the sensor will give a signal to the PLC this will stop the door motor.

The various input and output used are,

1) Door closing-\%Q00004

2) Door closing sensor-\%I00012

\subsection{Fire sensor logic}

As a safety measure a fire sensor has been fitted with the elevator cabin its logic has been described in the Figure 8 .

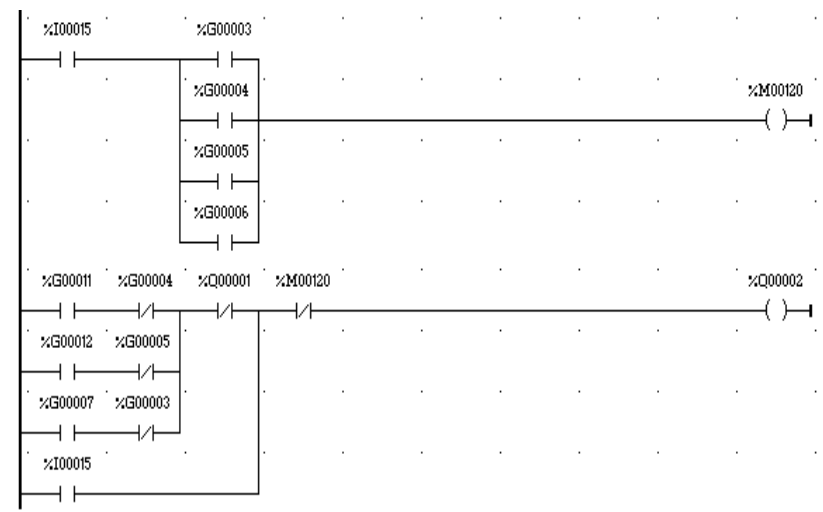

Fig 8: Ladder Logic for Fire Sensor

The input \%I00015 has been used as the input terminal for the fire detecting sensor. Once this input has been activated the PLC will initiate reverse motoring and also it is designed to stop the elevator in the nearest down floor.

\section{CONCLUSION}

Thus this chapter describes the entire circuit diagram and development of ladder logic. The developed ladder logic has been implemented by using VersaPro 2.02. Here the required inputs and outputs for elevators forward and reverse motoring, door opening and closing motor operation and various sensors present in every floor and at the end of both the door opening and door closing have been included in the logic and the program is interpreted.

\section{REFERENCES}

[1] Dae-Woong Chung, Hyung-Min Ryu, Young-Min Lee, Lo-Won Kang, Seung-Ki Sul, Seok-Joo Kang, Jun-Ho Song, Joong-Seok Yoon, Kil-Haeng Lee and Jong-Ho Suh (2001) 'Drive systems for high-speed gearless elevators', IEEE Industry Applications Magazine, vol. 7, pp 52-56.

[2] Darshil, Sagar, Rajiv, Pangaokar and S.A. Sharma (2008) 'Development of a PLC Based Elevator System with Colour Sensing Capabilities for Material Handling in Industrial Plant',Joint International Conference on Power System Technology and IEEE Power India Conference, pp 1-7.

[3] Eunsoo Jung, HyunjaeYoo, Seung-Ki Sul, Hong-Soon Choi and Yun-Young Choi, (2012) 'A Nine-Phase Permanent-Magnet Motor Drive System for an Ultrahigh-Speed Elevator', IEEE Transactions on Industry Application, vol. 48, pp 987-995.

[4] Gieras.J.F., Hartzenberg.P.D.,Magura.I.J.andWing.M.(1993)

'Control of an elevator drive with a single-sided linear induction motor', Fifth European Conference on Power Electronics and Applications, IET Conference Publications, p 353-358.

[5] Hong Sun Lim and Krishnan.R. (2007) 'Ropeless Elevator With Linear Switched Reluctance Motor Drive Actuation Systems', IEEE Transactions on Industrial Electronics, vol. 54, pp 2209-2218.

[6] Hong Sun Lim, Krishnan.R. andLobo.N.S.(2008) 'Design and Control of a Linear Propulsion System for an Elevator Using Linear Switched Reluctance Motor Drives', IEEE Transactions on Industrial Electronics, vol. 55, pp 534-542.

[7] Jae Sung Yu, Sun Mo Hwang and Chung-Yuen Won (2009) 'Performances of fuzzy-logic-based vector control for permanent magnet synchronous motor used in elevator drive system', 30th Annual Conference of IEEE Industrial,

[8] Jayawardana.H.P.A.P., Amarasekara.H.W.K.M.,Peelikumbura.P.T.S., Jayathilaka. W.A.K.C., Abeyaratne.S.G.andDewasurendra.S.D. (2011) 'Design and implementation of a statechart based reconFigureurable elevator controller', 6th IEEE International Industrial and Information Systems, IEEE Conference Publications, pp 352-357. 
[9] Jiang Jing and Zhang Xuesong (2011) 'Variable frequency speed-regulation system of elevator using PLC technology', 3rd International Conference on Advanced Computer Control, IEEE Conference Publications, pp 328-332.

[10] Knezevic.B., Blanusa.B.andMarcetic.D.(2011) 'Model of elevator drive with jerk control', XXIII International Symposium on Information, Communication and Automation Technologies, IEEE Conference Publications, pp 1-5.

[11] Ma Yinyuan and Jiang Zhaoyuan (2010) 'TaskOriented Analysis and Design Method for Developing PLC Programs for Mechanical System Control', International Conference on Measuring Technology and Mechatronics Automation, IEEE Conference Publications, vol. 3, pp 726-729.

[12] Onat.A., Kazan.E.,Takahashi.N., Miyagi.D., Komatsu.Y.andMarkon.S. (2010) 'Design andImplementation of a Linear Motor for Multicar Elevators', IEEE/ASME Transactions on Mechatronics, vol. 15, pp 685-693.

[13] Osama.M. and Abdul_Azim.O.(2008) 'Implementation and performance analysis of an elevator electric motor drive system', 12th International Middle-East Power System Conference, IEEE Conference Publications, pp 114-118.

[14] Peng Wang (2011) 'A Control System Design for Hand Elevator Based on PLC'IEEE Conference Publications, vol. 1, pp 77-74.
[15] Roncolatto.R.A., Romanelli.N.W., Horikawa.O., Hirakawa.A., Amancio.S.M.andSilverio. M. (2006) 'Automatic elevator system for maintenance services', IEEE 11th International Conference on Transmission \& Distribution Construction, Operation and Live-Line Maintenance.

[16] Torii.S., Izuno.N.,Watada.M.andEbihara.D. (2002) 'The design of the drive system of LSM for rope-less elevator using the maximum power point tracking control method', International Conference (Conf. Publ. No. 487) on Power Electronics, Machines and Drives, IET Conference Publications, pp 638-648.

[17] Vidanapathirana.A.C., Dewasurendra.S.D.and Abeyratne.S.G. (2011) 'Statechart based modeling and controller implementation of complex reactive systems', 6th IEEE International Conference on Industrial and Information Systems, pp 493-498.

[18] Wang Feng and He Fengyou (2010) 'Study of Hoist Perception System Based on IOT Technology', International Conference on Web Information Systems and Mining, IEEE Conference Publications, pp 357360 .

[19] Wei Gong, Huihui Wang and Lei Pan (2010) 'The Simulation and Analysis of High-Power-Factor and Energy Feedback of Elevator Drive System on Matrix Rectifier', International Conference on Intelligent Computation Technology and Automation, IEEE Conference Publications, vol. 3, pp 955-958.

[20] Xiaoling Yang, Qunxiong Zhu and Hong Xu, (2008) 'Design and Practice of an Elevator Control System Based on PLC',IEEE Conference Publications, pp 9499. 